\title{
CARTOGRAFÍA DE LAS ASOCIACIONES EDÁFICAS DEL BAIX VINALOPÓ
}

\author{
E. Matarredona
}

En el presente trabajo se realiza un estudio cartográfico de suelos del Baix Vinalopó, comarca alicantina de $487,6 \mathrm{~km}^{2}$ de superficie integrada por tres municipios: Elx, Crevillent y Santa pola.

La presencia de un suelo no puede definirse al margen del medio geográfico en el que se integra, dado que la incidencia de los factores geográficos en el proceso edáfico es tal que condiciona su evolución y diversidad. Por ello, hacemos referencia a una serie de criterios -geológicos, topográficos, climáticos, antrópicos- que explican la diversidad de las formaciones edáficas analizadas.

\section{FACTORES EDÁFICAS QUE CONDICIONAN LAS FORMACIONES EDÁFICAS DE LA COMARCA}

\subsection{La litología, como soporte mineral}

La historia geológica comarcal se vincula tanto a las trasgresiones y regresiones marinas como al diapirismo triásico, agente de las dislocaciones estructurales, aparte, según Montenat de la influencia provocada por los movimientos postorogénicos y procesos subsidentes observados en el sector meridional ${ }^{1}$.

1 MONTENAT, Ch., Les formations neogenes et quaternaires du Levant espagnol, Tesis Doctoral, Paris, 1973. GARCÍA ROSELL, L., Mapa Geológico de España E 1:200.000. Elche $n .^{\circ} 72$, IGME, 1973. PIGNATELLI, R., Mapa Geológico de España E 1:50.000. Elche n. ${ }^{\circ}$ 893, IGME, 1973. 
La alineación montañosa septentrional está constituida por un sustrato del Prebético d'Alacant, al que se superpone, sobre todo en la Serra de Crevillent, el Subbético alóctono, en parte recubierto por el Mioceno.

En esta unidad subbética, los afloramientos triásicos aparecen al E de la Serra de Crevillent en forma de margas abigarradas del Keuper, de vivos colores -rojos, verdes, amarilloscon importantes intercalaciones dolomíticas, visibles en la línea de cumbres. Asimismo, es importante el afloramiento del Keuper arcilloyesoso en la zona del Tabaiá y su sector oriental. Por su parte, el jurásico está representado en las calizas y dolomías que configuran el anticlinal de la Serra de Crevillent.

El cretácico de la unidad subbética aflora sólo en la zona de los Orones, a ambos lados de la carretera Crevillent-Aspe -en unas formas constituidas por calizas y margo-calizas del cretácico inferior- así como en las inmediaciones del pantano d'Elx. Mayor desarrollo presenta el cretácico en las unidades prebéticas; así, en la Serra de Crevillent las calizas y calizas margosas cretácicas quedan limitadas al $\mathrm{N}$ por los afloramientos jurásicos y al sur por la franja triásica.

Los afloramientos miocenos abundan en la comarca, sobre todo en la alineación montañosa septentrional donde se configuran una serie de pequeñas sierras miocenas que, en buena parte, recubren el substrato prebético y subbético alóctonos, destacando al S del Trias de Crevillent una gran superficie del Tortoniense superior cubierta por conglomerados y arcillas rojas villafranquienses que, según Montenat testimonian una intensa erosión. También la Serra de Santa Pola está formada por calizas miocenas protegidas por una espesa costra caliza de la formación Sucina (MONTENAT, 1973, 600-605).

El Plioceno, que aflora en la vertiente NW de la Serra de Santa Pola y en El Molar, está configurado por conglomerados, arenas y arcillas. Por otro lado, aparece en los glacis plioceno-villafranquienses, deformados y protegidos por una gruesa costra caliza, que se ubican en el sector oriental de la comarca (L'Altet, Balsars, N de Santa Ana, etcétera).

El Cuaternario abarca una gran extensión en la zona meridional. Se trata, fundamentalmente, de una formación detrítica cuyos materiales tienen su origen en la meteorización de los pertenecientes a las sierras adyacentes, configurando unas formaciones cuaternarias representadas por los glacis -que ocasionalmente muestran afloramientos de conglomerados y arcillas del Pleistoceno- y depósitos aluviales indiferenciados que tapizan los fondos de las áreas subsidentes. (El Fondó, El Saladar, el Clot de Galvany, etc.), sin olvidar los depósitos que forma el enorme cono aluvial del Vinalopó, en el centro de la comarca. 


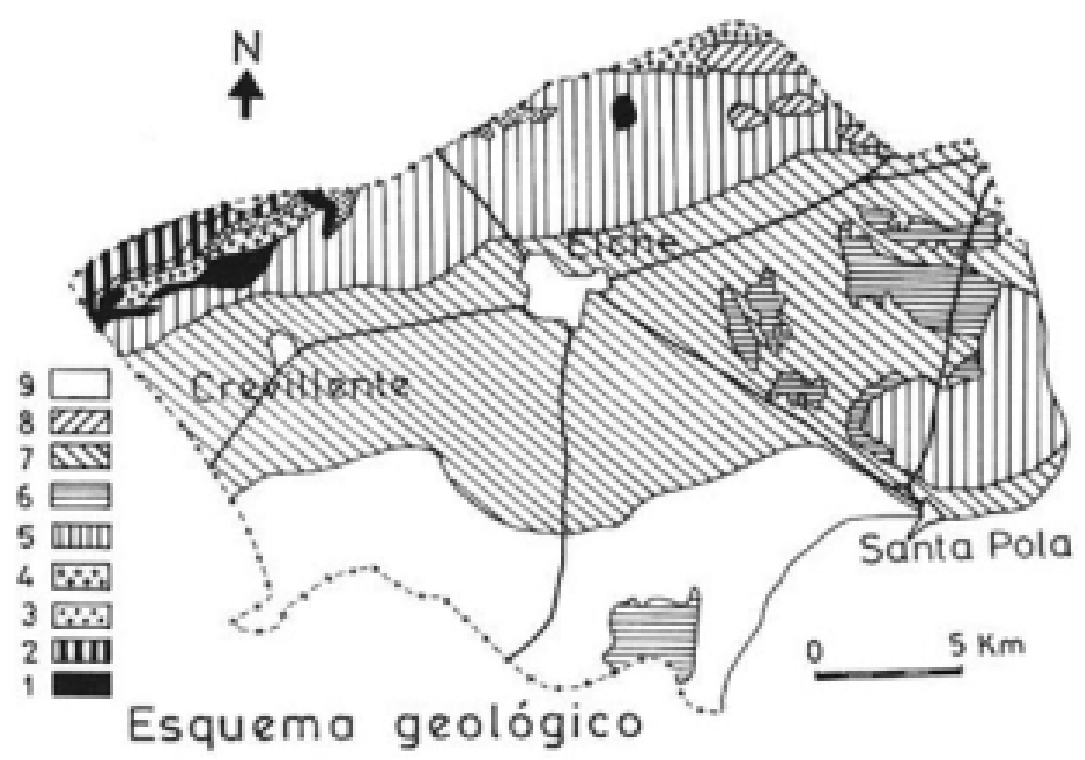

FIGURA 1. ESQUEMA GEOLÓGICO DEL BAIX VINALOPÓ. 1. Margas, arcillas y yesos del Keuper/Indiferenciado. Keuper-Suprakeuper. 2. Calizas, margo-calizas y margas del Jurásico. 3. Margas, margo-calizas y calizas del Cretácico Inferior. 4. Calizas del Cretácico Superior. 5. Margas vindobonienses del Mioceno. 6. Conglomerados, arenas y arcillas del Plioceno/Villafranquiense. 7. Glacis, conglomerados y arcillas del Pleistoceno. 8. Aluviales del Holoceno. 9. Cuaternario indiferenciado.

\subsection{La topografía}

El factor topográfico tiene un notorio papel en edafología puesto que la influencia de la altura y el nivel de pendientes es determinante en la configuración de las catenas de suelos. A este respecto, las unidades fisiográficas localizadas en el Baix Vinalopó son tres²:

- Una alineación montañosa septentrional, constituida por el anticlinal jurásico de la Serra de Crevillent -con orientación WSW-ENE- y su continuación oriental a través de una serie de pequeñas sierras miocenas, de menor envergadura (Alt del Muró, sinclinal del Tabaiá, anticlinal de Serra Grossa, y los de las sierras de Sancho, Borbuño y Colmenar).

2 GOZÁlvEZ, V., El Bajo Vinalopó. Geografía Agraria, Departamento de Geografía, Universidad de Valencia, Valencia, 1977, pp. 12-20. 
- Una llanura aluvial, constituida por el gran cono de piedemonte del Vinalopó y los glacis de acumulación desarrollados a ambos lados. Según Dumas se trataría de una llanura originada por una subsidencia postpliocena ${ }^{3}$ : mientras que Montenat, por su parte, la considera como una depresión tectónica que, de modo amplio, se presenta como un gran sinclinal entre los anticlinales interiores y los abombamientos costeros.

- Una franja costera en la que, salvo la Serra de Santa Pola que emerge en el Plioceno, el resto es cuaternario. Relieve cuaternario constituido por unas pequeñas cuencas de hundimiento en forma de depresiones costeras cerradas por restingas o por pequeñas colinas de calizas oolíticas (MONTENAT); depresión de la Salinera Catalana, el Fondó de la Senieta, el Clot de Galvany, el sinclinal de las salinas del Braç del Port y del Pinet; separadas por anticlinales (el de l'Altet, el de Santa pola, el del Molar). Al SW, a unos $10 \mathrm{~km}$ de la costa, el Fondó constituye otra zona de subsidencia cuaternaria.

\subsection{El clima, un parámetro básico}

El clima de la comarca se caracteriza por unas temperaturas invernales suaves -influencia marítima- y unas precipitaciones que no sólo se muestran escasas sino que traducen un comportamiento irregular ${ }^{4}$. En efecto, la cercanía al Mediterráneo y la topografía comarcal, actuando de pantalla a los flujos septentrionales, explican la existencia de unas temperaturas medias anuales no muy acusadas, y un comportamiento térmico mensual en el que destaca enero -como mes más frío- y agosto -como mes más cálido-, con una progresión irregular entre ambos.

Por su parte, las precipitaciones se muestran escasas -en torno a los $300 \mathrm{~mm}$ - y con un ritmo anual en el que la sequía estival es el rasgo más sobresaliente, mientras que el máximo pluviométrico coincide con el mes de octubre -como es normal en amplias zonas del sudeste peninsular-. Asimismo, es necesario referirse a la irregularidad interanual de estas precipitaciones que hacen muy problemáticos sus beneficios sobre la agricultura o su eficacia en el paisaje natural.

En conclusión, las altas temperaturas veraniegas, la indigencia pluviométrica y el carácter irregular de las precipitaciones explican unas tasas de aridez altas que inciden no sólo en la parada vegetativa del sector agrario y en sus rendimientos, sino también en la precariedad edáfica de algunas áreas.

\subsection{La vegetación, como acción permanente}

Salvo el caso excepcional de las masas boscosas de Quercíneas y pinares

3 DUMAS, B., Le Levant espagñol. La genèse du relief, Paris, 1977.

4 GOZÁLVEZ, V., op. cit., p. 20. 
de la Serra de Crevillent y algún manchón aislado de Pinus halepensis de las zonas más altas de la comarca, el dominio vegetal marca la preponderancia, sobre todo en las laderas de la franja montañosa septentrional, de un matorral calcícola con predominio de la alianza Thymo-Siderition, poblamiento de tomillares, especie endémica del SE peninsular, caracterizado por diversas especies de tomillo.

Aparte hemos de considerar una vegetación zonal adaptada a las características de determinadas formaciones edáficas: es lo que conocemos como «vegetación edáfica». Así, en los suelos Typic Gypsiorthids, desarrollados sobre litofacies del Keuper, aparece una cubierta vegetal escasa y raquítica de la alianza Gypsophilion formada por especies adaptadas a las altas concentraciones de sulfatos (yesos). Por otro lado, sobre los Aquollic salorthids y los Typic salorthid de los saladares, las características salinas determinan la aparición de una vegetación halófila, de colores grisáceos y hojas escasas, sobre todo, de especies como la sosa fina (Suaeda fruticosa), la sosa alacranera (Arthrocnemum fruticosum y diversas especies del género Limonium.

\section{FORMACIONES EDÁFICAS}

Siguiendo las propuestas metodológicas sugeridas en otras publicaciones ${ }^{5}$ en primer lugar se procedió a la selección de la escala de trabajo (1:100.000) y de la taxonomía apropiada (la llamada «clasificación americana ${ }^{6}$, así como se inició la búsqueda del material cartográfico necesario: Mapas Topográficos del Servicio Geográfico del Ejército E 1:50.000 y E 1:100.000, Mapas Geológicos del IGME E 1:50.000 y los fotogramas correspondientes del vuelo de 1956 (E 1:30.000).

En segundo lugar, se realizó una prospección de reconocimiento que tuvo como objetivo el conocimiento de una serie de factores físicos que supusiera una ayuda en la fase de foto interpretación, consistente en la búsqueda de áreas homogéneas definidas por una serie de elementos (litología, formas paisajísticas, vegetación, ocupación del suelo, pendientes, etc.); áreas homogéneas que, acopladas en un fotomosaico y reducidas a la escala de trabajo, nos permitieron una primera visión sobre la cartografía de suelos de la comarca.

A continuación, se procedió a verificar los niveles de información obtenidos en las fases anteriores para lo cual se establecieron una serie de «áreas piloto» que, una vez verificadas, fueron extrapoladas; al tiempo que se iban ela-

5 GUMUZZIO, J.-MATARREDONA, E., Formaciones edáficas del Campo de Alicante, Universidad de Alicante, Alicante, 1983. MATARREDONA, E., «Aplicación de la fotografía aérea en la cartografía de suelos», Investigaciones Geográficas, n. ${ }^{\circ}$ 3, Instituto Universitario de Geografía, Alicante, 1985. NIEVES, M.-TORCAL, L., Introducción a la práctica de la fotoedafología, INIA, Madrid. 1983.

6 SOIL SURVEY STAFF, Soil Taxonomy. A basic system of soil clasification for maping and interpreting surveys, 10 th. App., 1975. 
borando unas series taxonómicas y se extraían las correspondientes muestras de suelos en perfiles «tipo». Como conclusión fueron definidas una serie de asociaciones cartográficas delimitadas en el mapa correspondiente.

\subsection{Unidades taxonómicas}

\subsection{1. órdenes}

\section{Entisoles}

Los entisoles son aquellos suelos que normalmente no poseen otro horizonte de diagnóstico que no sea un epidedon ócrico o antrópico. Son suelos que o no poseen horizontes genéticos naturales o sólo presentan un comienzo de ellos.

Se caracterizan por presentar un perfil muy poco evolucionado; unas veces sobre materiales blandos, otras sobre rocas más duras. Incluyen, entre otros, muchos de los suelos llamados en otras sistemáticas, aluviales, regosoles, litosoles, e incluso, los suelos antrópicos.

El concepto central de entisol incluye los suelos de regolita profunda y las tierras que no tienen horizontes, excepto quizás una capa arable. Pueden tener cualquiera de los colores comunes a los suelos; puede haber roca firme a escasa profundidad o incluso el hombre puede haber formado un horizonte antrópico.

Dentro de este orden distinguimos los subórdenes psamment, fluvent y orthent. El primero está caracterizado por tener texturas gruesas, mientras que los fluvents no tienen contacto lítico, adosándose a los valles de los ríos ramblas y, finalmente, los orthents constituyen el concepto central. Un carácter distintivo de estos suelos lo constituye la presencia, a veces, de mantos superficiales pedregosos, especialmente en los fluvents.

\section{Inceptisoles}

Se encuentran, en general, en áreas con pequeñas pendientes; asociados a la casi totalidad de materiales litológicos presentes en la zona. Evidencian un cierto grado de evolución, lo que se traduce en mayores desarrollo del perfil y por la presencia generalizada de un horizonte cámbico, por encima del cual puede encontrarse un epipedon ócrico o antrópico.

Todos los inceptisoles localizados en la comarca, en base a los fuertes caracteres ócricos que presentan, quedan incluidos en el suborden ochrepts y más concretamente en el gran grupo xerochrepts (si admitimos el régimen xérico).

Todos los xerochrepts comarcales se desarrollan a partir de materiales originarios de naturaleza carbonatada, asociados a topografías llanas o suave- 
mente onduladas. El clima, la acción erosiva y la naturaleza lítica van a ser los principales condicionantes de su evolución.

A nivel de subgrupo encontramos una limitada variedad de tipos, que quedan caracterizados por las siguientes consideraciones generales:

* Calcixerollic xerochrepts. Presentan un horizonte cálcico, alto grado de saturación en bases y materiales originarios de naturaleza carbonatada.

* Petrocalcic xerochrepts. Término propuesto para aquellos xerochrepts desarrollados a partir de materiales originarios sobre costra caliza.

\section{Aridisoles}

Todos los suelos identificados dentro de este orden presentan deficiencias de agua durante largos períodos al año. En la edafogénesis de los horizontes de estos suelos implicados procesos halomórficos con dinámica y acumulaciones de sales en el perfil.

Afectados por escasas precipitaciones a lo largo del año, presentan, en períodos de mayor sequía, eflorescencias salinas en superficie; mientras que en épocas húmedas permanecen frecuentemente encharcados, dando evidencias de endorreismo.

Se localizan, casi exclusivamente, en áreas deprimidas endorreicas, asociadas a posiciones fisiográficas de fondo de valle o áreas de restinga litoral, con topografías llanas o suavemente onduladas, o en zonas aluviales próximas a formaciones margo-yesíferas del Keuper.

Todos los suelos de este orden quedan, a nivel de subórdenes, dentro de los orthids, caracterizados por proceder de sedimentos de erosión jóvenes y por la presencia de horizontes de acumulación de sales, bien sálicos o gypsicos. Se distribuyen en dos grandes grupos: salorthids y gypsiorthids.

Los salorthids presentan como resultado de una dinámica por capilaridad concentraciones de sales solubles en los horizontes sálicos. Ocupan depresiones en las que el manto freático satura al suelo durante algún período al año. Se localizan en las zonas endorreicas: saladares de l'Altet, Clot de Galvany, antigua albufera d'Elx, el Fondó, etc.

Los gysiorthids son menos frecuentes y se presentan en áreas próximas a formaciones margo-yesíferas del Keuper, su textura es menos arcillosa y presentan un horizonte gypsico. Se encuentran asociados a los xerorthent y los xerochrepts.

\subsubsection{Análisis de los perfiles}

Los perfiles seleccionados en la fase de verificación, a base de criterios de 
máxima representatividad, se analizan y describen en los cuadros adjuntos tomando como base las normas propuestas por la $\mathrm{FAO}^{7}$.

I. Este perfil se localiza sobre los sedimentos cuaternarios depositados en el Fondet dels Pinols, antiguo golfo del mar plioceno, situado al $\mathrm{N}$ de Torrellano. El suelo se caracteriza por un alto contenido en carbonatos en todos sus horizontes, unos $\mathrm{pH}$ básicos (entre 7,5 y 7,9) y una textura que pasa de francolimosa en superficie a limo en los horizontes inferiores.

Se trata de un suelo joven moderadamente bien drenado, que en el momento de la toma de muestra aparecía húmedo en los primeros $30 \mathrm{~cm}$ y que presenta una capacidad de retención en torno al $40 \%$ en los horizontes superiores, y del $56 \%$ en el inferior, donde el predominio de limo es patente.

II. Este perfil se desarrolla a partir de sedimentos pleistocenos que configuran una topografía de pequeñas colinas al S de l'Altet. Ofrece un horizonte A empardecido con presencia de materia orgánica, estructura poco desarrollada y muy pedregoso. Por debajo de este horizonte superficial se sitúan tres capas de costra caliza hasta el nivel de los $125 \mathrm{~cm}$. A más profundidad aparece una capa de caliza harinácea de color pardo pálido y textura franco-limosa.

III. Este perfil, situado sobre una pequeña superficie amesetada de la Serra de Santa Pola, se desarrolla a partir de sedimentos cuaternarios sobre material plioceno. Ofrece un primer horizonte de humus bruto de color pardo oscuro y estructura suavemente granular, muy pedregoso. A continuación, y hasta los $80 \mathrm{~cm}$ de profundidad, se localizan dos capas de costra caliza de color amarillento-rojizo que dejan paso a un horizonte fósil de limos rojos con alguna pequeña raicilla petrificada. Se trata de una formación fósil debida a fenómenos pedogenéticos acontecidos en un medio subacuático en un tiempo anterior en el que la pluviosidad y la temperatura fueron más elevadas que las actuales.

IV. Este perfil se obtuvo en el saladar situado al SW de Agua Amarga, en un punto que estuvo acondicionado en otro momento como salina. Se trata de un solontchak formado por influjo de aguas salobres hipogeas procedentes del nivel freático marino próximo a la superficie, que da unos perfiles inestables en función del nivel de fluctuación de dicha capa freática.

Se trata de suelos de perfil AC, textura franco-limosa en todos sus horizontes, estructura débil granular, adherentes, color pardo grisáceo-pálido, muy escasamente drenados y con una capacidad de retención superior al $45 \%$ en los niveles inferiores. El pH fluctúa entre el 7,9 y el 8,3 .

En ellos se observa, sobre todo en la estación seca, que el predominio de migraciones ascendentes por evaporación de la disolución salina, procedente del nivel freático próximo, provoca la aparición superficial de eflorescencias salinas blanquecinas.

V. Este perfil se obtuvo sobre una duna tirreniense oolítica situada al $\mathrm{W}$

7 Guías para la descripción de perfiles de suelos, FAO, Roma, 1977. 


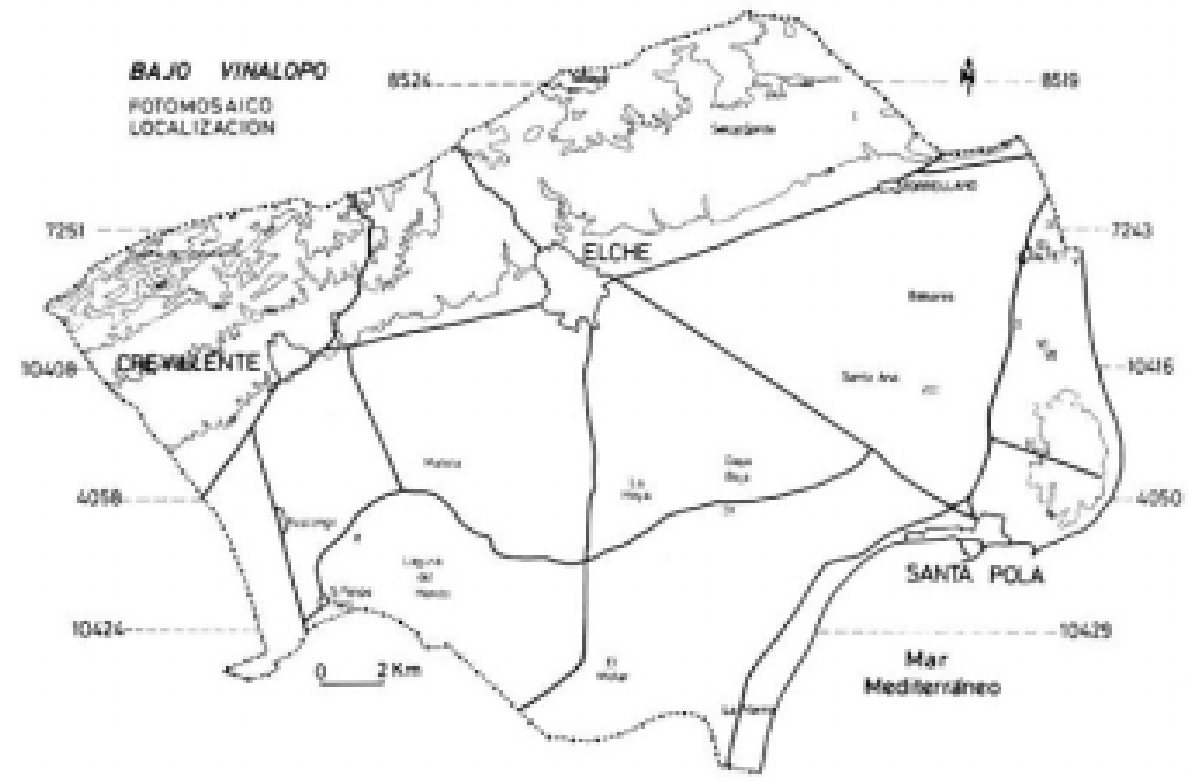

FIGURA 2. LOCALIZACIÓN Y FOTOMOSAICO DEL BAIX VINALOPÓ. Del I al X localización de los perfiles edáficos analizados. 
de Urbanova a una altura aproximada de unos $2 \mathrm{~m}$ sobre el nivel de la marjal de Agua Amarga próxima. Para su análisis «in situ» se aprovechó la existencia de una zanja de más de $1 \mathrm{~m}$ de profundidad, próxima a la salina -hoy abandonada-; zanja que nos permitió apreciar una acusada estratificación dunar protegida en superficie por una delgada costra que en algunos puntos ha desaparecido.

Se trata de una formación dunar -posible regosuelo sobre arenas- de perfil AC, textura arenosa franca, color castaño muy pálido -blanquecino- que presenta en superficie una raquítica vegetación psamófila, estructura granular en todo el perfil y un $\mathrm{pH}$ de 7,6, con una consistencia bastante dura en el horizonte inferior.

VI. Este perfil, obtenido en el fondo deprimido del Clot de Galvany -al N del camino del Carabassí- refleja las características de espacios sinclinales pliocuaternarios que aparecen rellenos de depósitos aluviales y fangos orgánicos cuya fracción clástica procede de la alteración de los limos rojos de los domos pliocuaternarios del Carabassí y colinas próximas.

Se trata de un solontchak, perfil AC, constituido sobre material cuaternario, de estructura débil granular, textura franco-limosa, $\mathrm{pH}$ en torno a 8, escasa capacidad de retención (32\%), que muestra en superficie una escasa vegetación de tipo lacustre.

VII. Este perfil, obtenido sobre el glacis septentrional de El Carabassí, a unos $10 \mathrm{~m}$ sobre el nivel del mar, con pendiente muy moderada, pudo analizarse aprovechando unas zanjas abiertas para la construcción de unas conducciones subterráneas actualmente abandonadas.

Se trata de un suelo pardo calizo de perfil A(B)C, textura franco-arenosa -en función de la proximidad a la zona deprimida situada al NW- que pudo posibilitar este tipo de depósito, y estructura granular. El horizonte superficial se presenta eluviado, de color parduzco claro, mientras que por debajo aparece un horizonte cámbico de color más oscuro. El pH fluctúa entre el 7,7 y 8,1 .

VIII. Este perfil se obtuvo sobre material cuaternario de un glacis de acumulación localizado en el K.3 de la carretera dels Bassars, en las proximidades de la ermita de San Pedro, en un área con aprovechamiento agrícola intensivo y moderadamente bien drenada.

Se trata de un suelo pardo calizo, de perfil A(B)C, textura franco-limosa, estructura subangular, consistencia blanda y contenido en carbonato cálcico bastante elevado. La capacidad de cambio es pequeña debido principalmente a las bajas proporciones de la fracción arcilla (menos del 40\%).

IX. Este perfil, desarrollado sobre depósitos cuaternarios, se localiza en el K-5 de la carretera de Bassars-La Foia, a unos $15 \mathrm{~m}$ sobre el nivel del mar, sobre la superficie del glacis-cono del Vinalopó. Está bien drenado y ofrece un aprovechamiento agrícola intensivo (cultivo de algodón en el momento de obtención de la muestra).

Se trata de un suelo pardo calizo profundo, de perfil $\mathrm{A}(\mathrm{B}) \mathrm{C}$, estructura 


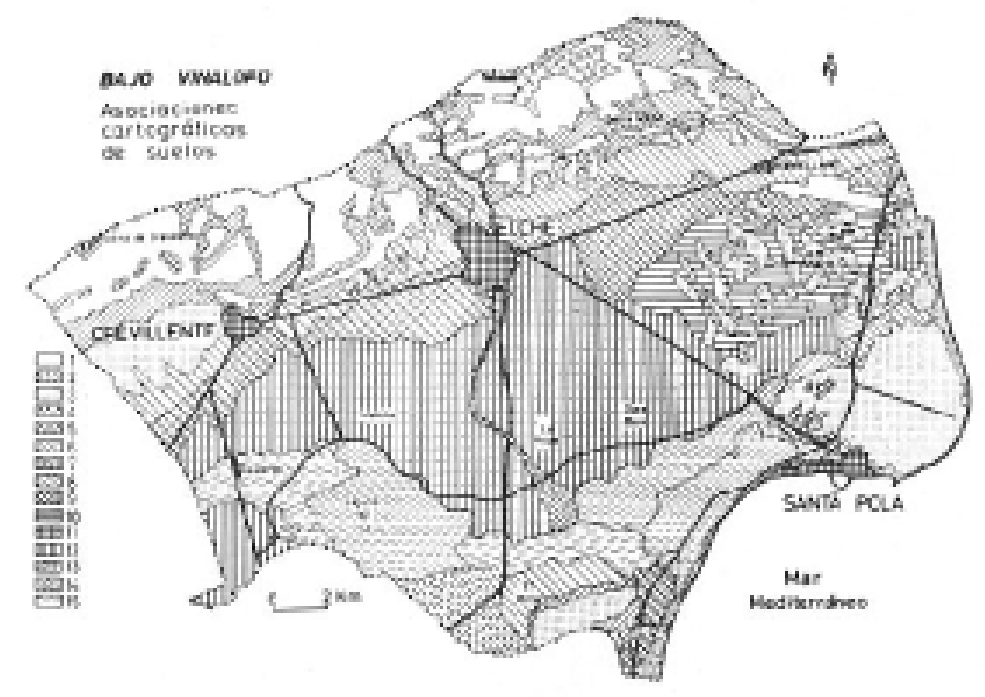

FIGURA 3. CARTOGRAFÍA DE ASOCIACIONES DE SUELOS. 1. Lithic xerorthents-Typic xerorthents. 2. Typic xerorthents-Lithic xerorthents-Typic xerofluvents. 3. Petrocalcic xerochrepts-Tipyc xerorthents-Lithic xerorthents. 4. Lithic xerorthents-Typic xerorthents-Typic gypsiorthids. 5. Typic xerorthents-Lithic xerorthents-Typic gypsiorthids. 6. Typic xerorthents-Aquollic salorthids-Typic salorthids. 7. Typic xeropsamment-Aquio xerorthents. 8. Typic xerorthents-Typic xerofluvents-Calcixerollic xerochrepts. 9. Typic xerorthents-Calcixerollic xerochrepts-Typic xerofluvents. 10. Calcixerollic xerochrepts-Petrocalcic xerochrepts-Typic xerorthents. 11. Calcixerollic xerochrepts-Typic xerofluvents-Petrocalcic xerochrepts. 12. Typic xerofluvents-Calcixerollic xerochrepts. 13. Typic xerofluvents-Aquollic salorthids. 14. Typic xerofluvents-Aquic xerofluvents. 15. Typic xerofluvents-Aquollic salorthids-Typic salorthids. 
subangular media, textura franco limosa en todos sus horizontes, color pardo pálido a muy pálido en los niveles inferiores y un $\mathrm{pH}$ que oscila de 7,8 a 8,2 .

$X$. Este perfil se obtuvo en el Fondó -proximidades a la vereda de Sendres- en una zona que mostraba claros indicios de eflorescencias salinas superficiales y que en la actualidad está siendo sometida a proceso de bonificación por parte del IRYDA.

En su análisis se aprecia un escaso drenaje y un horizonte en profundidad (a $85-90 \mathrm{~cm}$ ) de color verde-negruzco, quizás reflejo de un antiguo nivel de fondo lacustre colmatado en la actualidad.

Se trata de un solontchak de textura limosa o franco-limosa, estructura granular en los horizontes superiores, muy húmedo a partir de los $80 \mathrm{~cm}$ de profundidad y con un $\mathrm{pH}$ en torno a 8.

2.2. Asociaciones cartagrácicas de suelos

U.C. n. ${ }^{\circ} 1 \quad$ Lithic xerorthents

Typic xerorthents

Los suelos que componen esta unidad se desarrollan sobre materiales litológicos variados: desde los bancos de calizas blanquecinas y calizas nodulosas (en ocasiones, rojizas) jurásicas de la Serra de Crevillent a las areniscas calco margosas de los Orones y Serra Grossa, pasando por los conglomerados de la zona del Tabaiá.

Se trata de suelos azonales, delgados, que ocupan las topografías más elevadas de la comarca; suelos cuya evolución está condicionada, no sólo por esa naturaleza lítica aludida, sino también por una gran aridez, factores que posibilitan una fuerte erosión y una evolución de continuo rejuvenecimiento. Son formaciones edáficas poco evolucionadas en función de su posición fisiográfica, de naturaleza pétrea, diaclasados y atacados por meteorización.

Son suelos con un aprovechamiento agrícola bajo, por no decir nulo, prácticamente improductivos. Expresa referencia hace Cavanilles a ellos al cruzar el arco montañoso septentrional de la comarca: «...apenas se entra en este camino (Aspe-Elche) muda el suelo de aspecto. A las frondosas huertas de los pueblos que acabamos de ver, se siguen cerros áridos de tierra blanquecina, lomas y gargantas sin cultivo, sin árboles y casi sin arbustos por más de una legua hasta Carrús». (CAVANILLES, II, 269).

Se localizan en la franja montañosa septentrional de la comarca que de W a E, desde la Serra de Crevillent hasta el Colmenar, va sensiblemente descendiendo de altura. 

U.C..$^{\circ} 2$
Typic xerorthents
Lithic xerorthents
Typic xerofluvents

Se desarrolla esta unidad sobre material litológico muy variado: calizas margosas blancas y rojas del Cretácico, en las vertientes del Puntal de Matamoros; margas ocres cretáceas en Torrellano Alto; margas miocenas en Santa Ana y Pinols; areniscas pliocenas en la vertiente septentrional de la Serra de Santa Pola y calcarenita gruesa en las Planas de La Marina.

Se presentan en laderas con pendientes moderadamente escarpadas, en los piedemontes más elevados de las estructuras montañosas, citadas en la unidad anterior, así como asociados a ciertos sectores de pequeños glacis (Serra de Santa Pola, el Molar, entre otros).

La mayoría de las unidades taxonómicas de esta asociación -litosuelos, regosuelos, xerodendzinas- que se presentan en laderas de pendientes medias, están poco evolucionados y ofrecen una pedregosidad variable -visible en algunos casos- por la cercanía a los afloramientos circundantes próximos. Son suelos poco evolucionados, sin una organización definida de los horizontes edáficos, presentando -ocasionalmente- visibles acumulaciones de carbonato cálcico. Su poca evolución está condicionada tanto por la intensidad de la erosión (en relación a su posición fisiográfica) como por la naturaleza de sus materiales que controlan los procesos erosión-aporte.

El aprovechamiento es de escaso valor: matorral calcícola (en la franja septentrional) que se muestra alternante con un aterrazado aprovechamiento de secano y matorral gypsícola, al sur, en las estribaciones de la Serra de Santa Pola.

\section{U. C. n. $3 \quad$ Petrocalcic xerochrepts \\ Typic xerorthents \\ Lithic xerorthents}

Esta unidad abarca una extensa área situada en el sector oriental y piedemonte del arco montañoso septentrional, así como zonas de la Serra de Santa Pola y el Molar, que se encuentra cubierta por una espesa capa de caliche, situada en algunos casos sobre un glacis-costra de nula pendiente o en otros, configurando un paisaje ligeramente alomado que tan sólo posibilita una vegetación esteparia, salvo en determinados puntos en los que el menor espesor de la capa caliza y la acción antrópica han posibilitado el acceso a unos suelos mejores, situados por debajo de la costra.

Con todo, si la costra calcárea aflora, circunstancia que sucede en esta unidad con cierta frecuencia, es posible señalar la presencia de unos raquíticos suelos solamente colonizados por algunos líquenes y, en general, una rala cobertura vegetal que matiza un paisaje estepario. 
Cuando la costra caliza está a algunos centímetros de la superficie, se encuentra cubierta por una capa de suelo pedregoso, pardo o rojizo, calizo, desarrollado sobre sedimentos coluviales relativamente recientes que yacen sobre la costra: «compónense los cerros de greda y cantos rodados en capas casi horizontales sumamente duras, que rotas a pico y desmenuzadas forman un suelo apto para viñas, algarrobos y olivos» (CAVANILLES, II, 275).

\author{
U.C. n. ${ }^{\circ} 4 \quad$ Lithic xerorthents \\ Typic xerorthents \\ Typic gypsiorthids
}

Estos suelos se desarrollan sobre litofacies del Keuper que incluyen margas abigarradas con niveles de yesos, asociadas ocasionalmente a dolomías de grano fino gris muy brechificadas (Alt del Forat). Se localizan en topografías muy accidentadas, con fuertes pendientes que, ayudadas por la naturaleza fácilmente erosionable de los materiales, posibilitan profundos encajamientos en los procesos de escorrentía.

Precisamente, esas pendientes acusadas y su alta erosionabilidad explican la existencia de formaciones edáficas poco evolucionadas, de perfil AC, que presentan, en ocasiones, horizontes gypsicos.

El aprovechamiento de esta unidad se resume a un matorral xerofítico en el que predominan especies del orden Gypsofiletalia adecuadas a esos condicionamientos: se trata de matas de escaso tamaño, con escaso aporte de materia orgánica.

Esta unidad se localiza en lugares muy puntuales de la vertiente meridional de la Serra de Crevillent (Alt del Forat) y en las proximidades del pantano d'Elx (Ferriol).
U.C..$^{\circ} 5$
Typic xerorthents
Lithic xerorthents
Typic gypsiorthids

Los suelos de esta unidad se localizan, como en el caso anterior, sobre las margas abigarradas yesíferas del Trias que afloran en las inmediaciones de l'Alt del Forat y al $\mathrm{N}$ de las Vallongas (zona oriental del Tabaià).

Topográficamente se localiza en áreas de pendiente más moderada que la unidad 4; por ello, la acción erosiva se deja sentir con menos fuerza, pese a que los condicionamientos líticos se muestran favorables a dicha acción. El aprovechamiento, asimismo, se vincula a un matorral xerofítico, poco exigente tanto en materia edáfica como en condicionamientos climáticos. 

U.C..$^{\circ} 6$
Typic xerorthents
Aquollic salorthids
Typic salorthids

Los suelos que forman esta asociación -salinos por su ubicación próxima al litoral y por su morfología- se desarrollan a partir de depósitos cuaternarios arcillo limosos con aportaciones salinas marinas. Son suelos de origen aluvial producidos, durante el Holoceno, por colmatación de la antigua albufera gracias a los aportes del Vinalopó.

Se trata de suelos jóvenes, sin desarrollo de horizontes edáficos, con nivel freático próximo a la superficie -oscila entre $(-2 \mathrm{~m})$ y la superficie- y de alta salinidad. Todo ello condiciona un aprovechamiento agrícola nulo, dado que estos condicionamientos sólo posibilitan la existencia de una vegetación halófila, sobre todo, especies fruticosas anuales y diversas especies del género Limonium.

Los altos contenidos salinos y su propia ubicación, así como las elevadas tasas de evaporación que facilitan las concentraciones salinas en superficie, han posibilitado el aprovechamiento de estas áreas como zonas salineras, actualmente abandonadas en gran parte (L'Altet, El Pinet), pero otras en explotación (Santa Pola) como único recurso factible de unos suelos que agrícolamente son improductivos.

Aparte de las zonas citadas por su aprovechamiento en la obtención de sal, esta unidad se localiza en ciertos entornos más interiores: saladares del Realengo, d'Elx, del Clot de Galvany; áreas que ya Cavanilles cita en el s. XVIII: «... eran en otro tiempo un suelo yermo, salobre, baxo, húmedo y muchas veces anegado, donde crecían salicornias, sálsolas y multitud de plantas que aman la humedad» (CAVANILLES, II, 280).

Se trata de suelos del tipo solontchak calco-sódico en los que el perfil de tipo AC, poco diferenciado, presenta una estructura floculada en los horizontes humíferos, siendo frecuente que en épocas de fuerte evaporación las sales se acumulen en superficie, provocando la formación de eflorescencias salinas e, incluso, ocasionalmente, una verdadera costra salina.

U.C. . $^{\circ} 7$ Typic xeropsamment

Aquic xerorthents

Morfológicamente se estructura como un cordón de dunas litorales, con una vegetación que ha sufrido una fuerte regresión como consecuencia de la acción antrópica, urbanizaciones, complejos residenciales).

Litológicamente se ubica sobre formaciones de dunas de grano fino y color grisáceo, situadas en la zona de los Arenales del Sol, El Pinet y La Marina.

Los suelos arenosos que constituyen esta asociación son poco evolucionados, presentan unas texturas gruesas, dado su desarrollo sobre arenales costeros -la gramilometría de un horizonte medio de un perfil analizado entre Ur- 
banova y los Arenales del Sol permite calificarlo de arenoso-franco-. Se trata de regosuelos que pueden adscribirse, en algún caso, al tipo de yerma de arenas de la clasificación de Kubiena.

\author{
U.C. . $^{\circ} 8 \quad$ Typic xerorthents \\ Typic xerofluvents \\ Calcixerollic xerochrepts
}

Los suelos de esta unidad se sitúan a modo de una estrecha franja sensiblemente paralela a la carretera Alicante-Murcia (N-340), en la parte alta del glacis que desciende desde la alineación montañosa septentrional (Serra del Colmenar, alineaciones meridionales de la Serra Grossa, etc.), franja que se estrecha hacia el área occidental (estribaciones de la Serra de Crevillent). También aparecen en la vertiente septentrional de El Molar -entre las isohipsas de 30 y 10 m (desde el canal del Progreso hasta los Azarbes)- y al N y W del Carabassí (en el piedemonte de la Serra de Santa Pola).

Se trata de una asociación de regosuelos, xerorendzinas y suelos pardo calizos (en menor proporción), entes pedológicos que se encuentran asociados a topografías de pendientes moderadas y que se desarrollan a partir de sedimentos cuaternarios constituidos por materiales resultantes de la erosión de margas y calizas de las formaciones miocenas y pliocenas aledañas.

\author{
U.C. n. ${ }^{\circ} 9 \quad$ Typic xerorthents \\ Calcixerollic xerochrepts \\ Typic xerofluvents
}

Esta unidad se diferencia de la anterior no sólo por su localización -en el tramo medio del glacis- sino también por la menor pedregosidad y, consiguientemente, por las mayores posibilidades de aprovechamiento del suelo, dedicado, sobre todo, a cultivos de regadío.

Se localiza es una amplia banda que de $\mathrm{E}$ a W discurre sensiblemente paralela -en algunos casos a ambos lados- de la N-340 (Alicante-Murcia).

Se trata de suelos calcáreos que ofrecen un epipedon ochrico de poco espesor y que se forman a partir de depósitos calcáreos en una matriz limo-arcillosa procedentes de la erosión de calizas y margas de las formaciones próximas.
U.C. n. ${ }^{\circ} 10$
Calcixerollic xerochrepts
Petrocallic xerochrepts
Typic xerorthents

Los suelos que componen esta asociación -pardo calizos profundos en su mayoría- se desarrollan en depresiones rellenadas por materiales blandos: margas y arcillas terciarias y material cuaternario. 
Son suelos moderadamente pedregosos, ofrecen un epipedon ochrico con un límite inferior brusco -cuando reposa libremente sobre material subyacente-, o bien gradual -cuando pasa a un horizonte cámbico-. No se aprecian indicios de traslocación de carbonatos en el perfil, a pesar de que, ocasionalmente, puedan presentarse superficies encostradas.

Se localizan al E del cono del Vinalopó, configurando un paisaje caracterizado por amplios canales o canyades de orientación paralela al desarrollo del cono (NW-SE), canales que se ramifican entre una variada gama de afloramientos de costra caliza (con 3 ó $4 \mathrm{~m}$ de desnivel) y que en ocasión de alguna precipitación acusada pueden ser funcionales ${ }^{8}$.

Se trata de áreas con un aprovechamiento agrícola bueno, ocupadas, normalmente, por cultivos arbóreos (almendros, sobre todo).

\section{U.C. n. ${ }^{\circ} 11 \quad$ Calcixerollic xerochrepts \\ Typic xerofluvents \\ Petrocallic xerochrepts}

Los tipos de suelos que componen esta asociación marcan un predominio de suelos pardo calizos en complejo con regosuelos y algún afloramiento de costra caliza. Se desarrollan a partir de los materiales del glacis-cono del Vinalopó, fundamentalmente en el sector central, puesto que al W, en tierras crevillentinas, los suelos configurados sobre glacis ofrecen una mayor pedregosidad (zona de El Pedriscal y áreas situadas al S del canal de Albatera).

Con todo, en general, son moderadamente pedregosos, no apreciándose indicios de traslocación de carbonatos en el perfil, a pesar de que, circunstancialmente, pueden presentarse superficies encostradas.

Se trata de un área con un notorio aprovechamiento agrícola -cultivos herbáceos de regadío, frutales, agrios- puesta ya de manifiesto por Cavanilles cuando exalta la excelencia de los campos de los alrededores d'Elx «... donde destinaron a palmas las tahúllas contiguas a los edificios de la villa, ...Síguese a esa faxa circular de huertos otra más ancha donde se cultivan trigos, barrillas, alfalfas y otras plantas útiles, y últimamente vienen los olivos... y sirven de corona o cerco al resto de las huertas» (CAVANILLES, II, 270).

U.C. n. ${ }^{\circ} 12 \quad$ Typic xerofluvent

Calcixerollic xerochrepts

Esta asociación se circunscribe al sector SW de la comarca -en torno a San Felipe de Neri, al S del azarbe del Riacho-, zona conocida por La Huerta, ubicada por debajo de la isohipsa de los $10 \mathrm{~m}$; zona de antiguos saladares saneada por el cardenal Belluga en el siglo XVIII.

Predominan los suelos aluviales -conocidos como suelos de vega

8 GOZÁLVEZ, V., op. cit., p. 17. 
parda-, entendidos como formaciones edáficas constituidas sobre sedimentos cuaternarios, aportados hacia esta zona de colmatación tanto por el Segura como por el Vinalopó, que posibilitan unos suelos de textura franco-arcillosa limosa que ofrecen una ligera acumulación de materia orgánica en los primeros $30-40 \mathrm{~cm}$ de profundidad.

Son suelos fuertemente calizos, con valores dominantes de carbonato cálcico del $50 \%$ -por ello, débilmente alcalinos- que dan un $\mathrm{pH}$ inferior a 8 . Suelen presentar un horizonte superficial humífero antrópico (Ap), horizontes de transformación química y acumulación de hierro y yesos (B) y horizontes inferiores grises de reducción $(\mathrm{G})$.

En determinadas áreas, en el subsuelo se encuentran capas impermeables arcillosas que mantienen el nivel freático a una profundidad de alrededor de $1 \mathrm{~m}$, nivel que, por otro lado, se muestra fluctuante en relación al régimen pluviométrico. Presenta aptitud excelente para cultivos herbáceos.

U.C. n. ${ }^{\circ} 13$

Typic xerofluvent

Aquollic salorthids

Esta unidad se localiza al S de la comarca, ocupando los antiguos almarjales de Bassa Llarguera en Els Carrisals -zona bonificada por el marqués d'Elx en el siglo XVIII.

Presenta notorias semejanzas con la unidad anterior: formación similar -zona de colmatación de aluviones cuaternarios depositados por el Vinalopó-, funcionamiento como almarjal y saladar hasta el siglo XVIII, proceso de bonificación posterior, etc.; pero en esta zona de Els Carrissals el proceso de lavado no ha sido tan positivo como en el área de San Felipe de Neri: los suelos muestran unos porcentajes de sal superiores -la desalinización ha sido insuficiente- y los rendimientos son, evidentemente, más bajos.

Se trata de suelos formados sobre limos negros -deposición provocada por una transgresión marina de marisma- aparte de limos rojos y cantos encostrados, que se manifiestan superficialmente con unos suelos grises dedicados fundamentalmente a cultivos herbáceos de regadío, con una capacidad de uso inferior a la anterior.

$\begin{array}{ll}\text { U.C. n. } & \text { Typic xerofluvent } \\ \text { Aquic xerofluvent }\end{array}$

Los suelos que componen esta unidad se desarrollan a partir de sedimentos fluviales de naturaleza heterogénea, que incluyen depósitos aluviales de ramblas y barrancos. La morfología de los depósitos presenta una heterometría variable.

En conjunto, son suelos poco evolucionados que carecen de organización edáfica pese a que, con cierta frecuencia, presentan estratificación de los materiales subyacentes. En ocasiones, ofrecen en superficie un horizonte antrópi- 
co y, a menudo, cambios bruscos de color, textura y estructura que se corresponden con las discontinuidades litológicas en la sedimentación.

Esta unidad se localiza, preferentemente, en el tramo final del cono de deyección del Vinalopó por debajo de la isohipsa de $\operatorname{los} 15 \mathrm{~m}$. Se trata de un espacio no cultivado que presenta un escaso aprovechamiento.

\author{
U.C. n. ${ }^{\circ} 15 \quad$ Typic xerofluvent \\ Aquollic salorthids \\ Typic salorthids
}

Esta unidad podría considerarse como una degradación de la n. ${ }^{\circ} 13$; es decir, se trata de un área de saladar sometida a un proceso de bonificación, proceso que no ha logrado el objetivo perseguido tanto por la elevada salinidad como por la falta de agua necesaria para llevar a cabo la desalinización. Todo ello ha determinado una formación edáfica que sin alcanzar los grados extremos de salinización de la unidad . $^{\circ}$ 6, tampoco ofrece las garantías y posibilidades de otros espacios bonificados (San Felipe de Neri y Els Carrissals).

Se trata de suelos formados sobre depósitos aluviales que presentan una acusada presencia de cloruros -sódico y cálcico- en su composición; es decir, suelos del tipo solontchak calcosódicos asociados a los clásicos suelos de vega, que hacen muy problemático su aprovechamiento.

Se localiza en una franja al $\mathrm{N}$ del azarbe del Riacho y S de la vereda de Orihuela -zona de los alrededores de El Realengo que fue objeto de un proceso bonificador, con escaso éxito, a cargo del Instituto Nacional de Colonización en 1946- ${ }^{9}$; así como en la zona llamada El Porvenir, al S de la vereda de Sendres, actualmente inmersa en obras de colonización promovidas por el IRYDA. También aparece al N de Els Carrissals y en El Molar.

\title{
3. CAPACIDAD DE USO DE LOS SUELOS
}

El mapa de capacidad de uso de los suelos surge como aplicación del mapa de asociaciones cartográficas de suelos que hemos propuesto en el apartado anterior, agrupándolos en función de sus potencialidades y limitaciones.

A este respecto hemos seguido los criterios propuestos por el Soil Conservation Service, sometidos a determinadas restricciones que sólo nos han permitido trabajar en el ámbito de la clase y subclase -como unidades fundamentales-, lo que, por otro lado, ha limitado a cinco las clases utilizadas.

9 LÓPEZ GÓMEZ, A-ROSSELLÓ, V., Geografía de la provincia de Alicante, Diputación Provincial, Alicante, 1978, pp. 33-37. 


\subsection{Clase A}

Dentro de esta clase incluimos los suelos aluvio-coluviales, algún pardo calizo y los transformados por el riego, situados bien sobre el glacis-cono del Vinalopó -asociación n. ${ }^{\circ} 11$ o bien en áreas bonificadas de antiguos saladares en las proximidades de San Felipe de Neri -asociación n. ${ }^{\circ} 12-$.

Incluyen suelos jóvenes, en función de la naturaleza reciente de los materiales -cuaternarios-, con inclusiones, en algunas áreas del sector SW (zona de La Huerta) de manchones de antiguos solontchaks actualmente transformados y bonificados por el riego.

Las topografías dominantes son llanas, su espesor suele ser superior a los $40 \mathrm{~cm}$ y no presentan pedregosidad o elementos groseros que impidan la mecanización. Se encuentran sometidos a régimen de regadío.

Quedan localizados en una franja central, situada al S de la carretera N-340 Alicante-Murcia, que va desde las inmediaciones de Algorda y Matola hasta la carretera que une Elx con Santa Pola; así como el extremo SW, zona de La Huerta, situada en los alrededores de San Felipe de Neri.

\subsection{Clase B}

Se incluyen en esta clase tanto los suelos pardo calizos sobre calizas y margas situados en la parte alta de los glacis comarcales como los suelos pardo calizos aluvio-coluviales de cotas más bajas, así como determinadas xerorendzinas sobre materiales calizos y margosos y algunos «antiguos» solontchaks, reconvertidos en la actualidad. Es decir, hemos incluido suelos pertenecientes a los órdenes inceptisoles -calcixerollic xerochrepts y petrocalcic xerochrepts- y antisoles -typic xerorthents y typic xerofluvent-, correspondientes a las asociaciones números 8 , 9,10, y 13.

En general, los suelos de esta clase se caracterizan por su ubicación en topografías llanas o suavemente onduladas, con pendientes moderadas. En superficie muestran algún elemento grosero que no impide el empleo de maquinaria delicada.

Se ubican en una franja situada al pie de la alineación montañosa septentrional que de $\mathrm{E}$ a W va desde l'Altet hasta el piedemonte de la Serra de Crevillent. Asimismo, en el sector meridional, en los alrededores de El Molar, La Marina y zona de Els Carrissals. También podemos englobar en esta clase el sector $\mathrm{W}$ de la asociación n. ${ }^{\circ} 11$-zona de El Pedriscal y proximidades de la estación de Crevillent- en el que la pedregosidad del suelo, por su configuración sobre la superficie del glacis, determina unas limitaciones ostensibles a las formaciones edáficas.

\subsection{Clase C}

Los suelos pertenecientes a esta clase presentan una capacidad de uso in- 


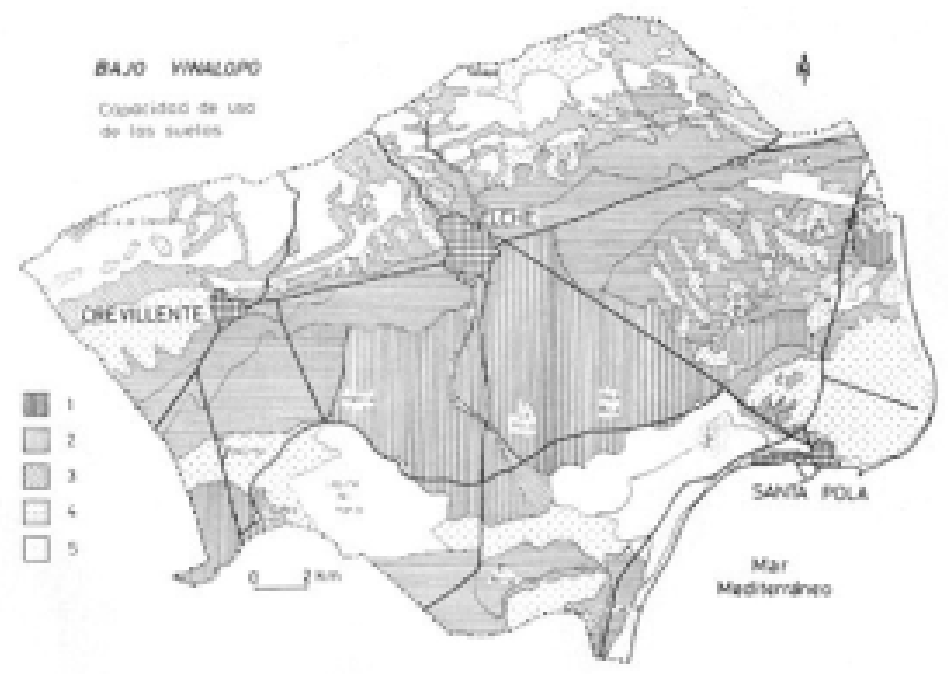

FIGURA 4. CAPACIDAD DE USO DE LOS SUELOS. 1. Clase A. 2. Clase B. 3. Clase C. 4. Clase D. Clase E. 
ferior a la clase precedente, de ahí que, sobre todo, se empleen para olivo y almendro.

Incluimos los suelos localizados en el piedemonte de la estructura montañosa septentrional -fundamentalmente, regosoles sobre margas- así como alguna xerorendzina y algún pardo calizo sobre materiales aluviocoluviales -con caracteres hidromorfos- localizados en el cono de deyección del Vinalopó (en las proximidades de Els Carrissals). Todos ellos corresponden a las asociaciones números 2 y 14.

En general, la fisiografía es más ondulada que en los casos anteriores, sobre todo en lo que respecta a la asociación número 2 , de ahí que los riesgos de erosión sean de moderados a altos; presentando, por otro lado, cierto déficit de agua en el período estival.

Se extienden por las vertientes de las estructuras montañosas comarcales -con pendientes superiores, en algún caso, al 8\%-, Serra de Crevillent, Serra Grossa, Serra del Colmenar, etc., así como en el tramo final del cono de deyección del Vinalopó.

\subsection{Clase D}

Pertenecen a esta clase aquellos suelos no susceptibles de utilización agrícola, dotados de una baja capacidad de uso y, en general, dedicados a monte bajo, cubierto por un escaso y raquítico matorral. Incluimos los lithic xerorthents y typic xerorthents del orden entisol; los typic gypsiorthids, aquollic salorthids y typic salorthids del orden aridisol; y algún petrocalcic xerochrepts de los inceptisoles; correspondientes, todos ellos, a las asociaciones cartográficas números $3,4,5$ y 15.

En general, son suelos que se caracterizan por un espesor efectivo en torno a los $25 \mathrm{~cm}$, donde los riesgos de erosión afectan sobre todo a los suelos de las unidades 3 y 4 , en los que los efectos erosivos constituyen el factor dominante de limitación, mientras que la unidad $n .^{0} 5$ muestra una gran limitación en la zona radicular motivada tanto por la baja capacidad de agua utilizable como por las características de los materiales triásicos constituyentes. Por su parte, la salinidad en la unidad 15 puede provocar ciertas limitaciones a los cultivos.

Se extienden por ciertos espacios puntuales de la Serra de Crevillent y N de las Vallongas, así como en determinados lugares del piedemonte serrano crevillentino -al W del municipio-, donde hay un marcado afloramiento de conglomerados y arcillas rojas villafranquienses. Asimismo, en ciertas áreas donde afloran retazos de glacis cuaternarios antiguos protegidos por gruesas costras calizas (al S de l'Alt de la Peña, S de Serra Grossa, Balsars, l'Altet, etc.) y en algunas zonas endorreicas meridionales -superficies de saladares- donde el hidromorfismo y los grados de salinidad imponen sus limitaciones (el Saladar -en las proximidades de El Realengoy Els Carrissals -entre el azarbe de Dalt y el del Robatorio-). 


\subsection{Clase E}

Quedan incluidos en esta clase aquellos suelos no susceptibles de empleo agrícola, con profundas limitaciones, entre las que destaca su escaso espesor efectivo y donde los riesgos de erosión pueden alcanzar valores elevados en topografías abruptas y de pendientes acusadas.

Pertenecen a esta clase los lithic xerorthent y typic xeropsamment del orden entisol, y los typic salorthid y aquollic salorthids del orden aridisol, correspondientes a las asociaciones números 1,6 y 7.

Se sitúan en posiciones fisiográficas dispares; así, mientras que los lithic xerorthent (litosuelos) ocupan las posiciones más elevadas, los typic xeropsamment (regosuelos sobre arenas) se localizan sobre las formaciones dunares litorales, y los solontchaks calcosódicos (típicos de los saladares) quedan ubicados en la banda endorreica meridional.

El subtipo Ee -correspondiente a la unidad 1- presenta muchos elementos pedregosos que impiden el empleo de maquinaria ligera, mientras que el Es -presente en la unidad 6- está afectado por la salinidad, dado el carácter de albufera litoral en proceso de colmatación, que introduce severas limitaciones por los altos contenidos de sales.

Se localizan en la alineación montañosa septentrional, desde la Serra de Crevillent hasta las de Sancho y Colmenar; también en los espacios endorreicos (laguna del Fondó, antigua albufera d'Elx, salineras de l'Altet, Clot de Galvany) y en el cordón arenoso litoral (Arenales del Sol, Cabo de Santa Pola y playas de Santa Pola y del Pinet). 


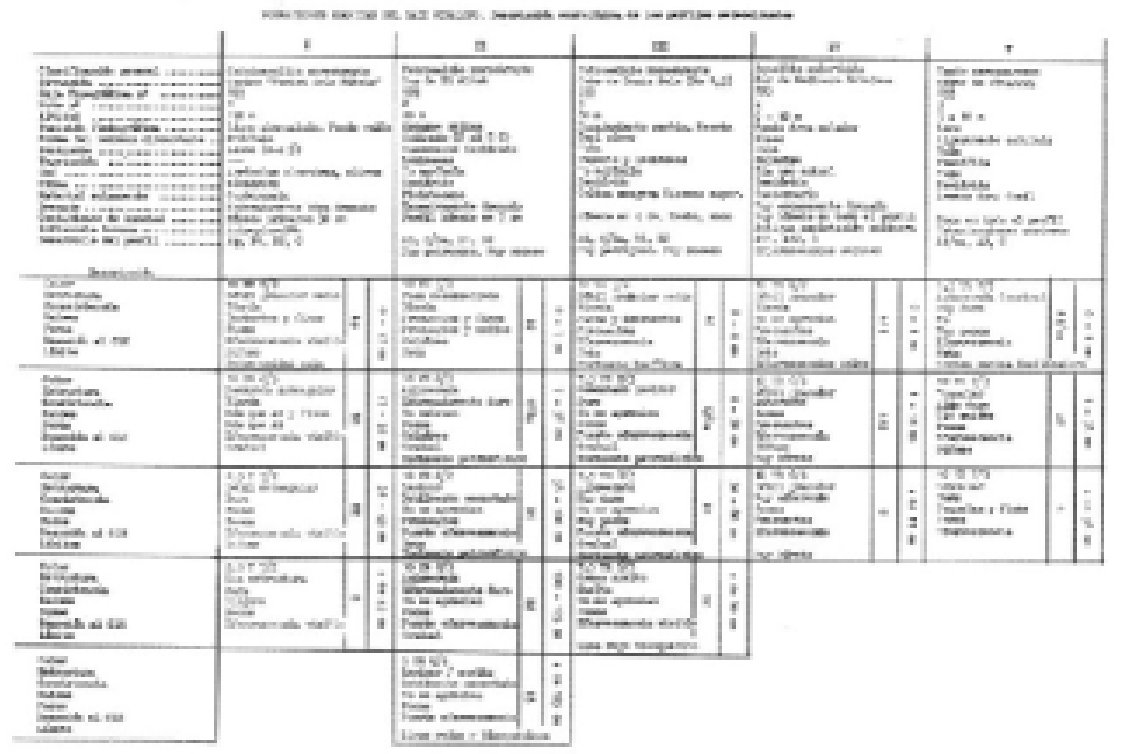




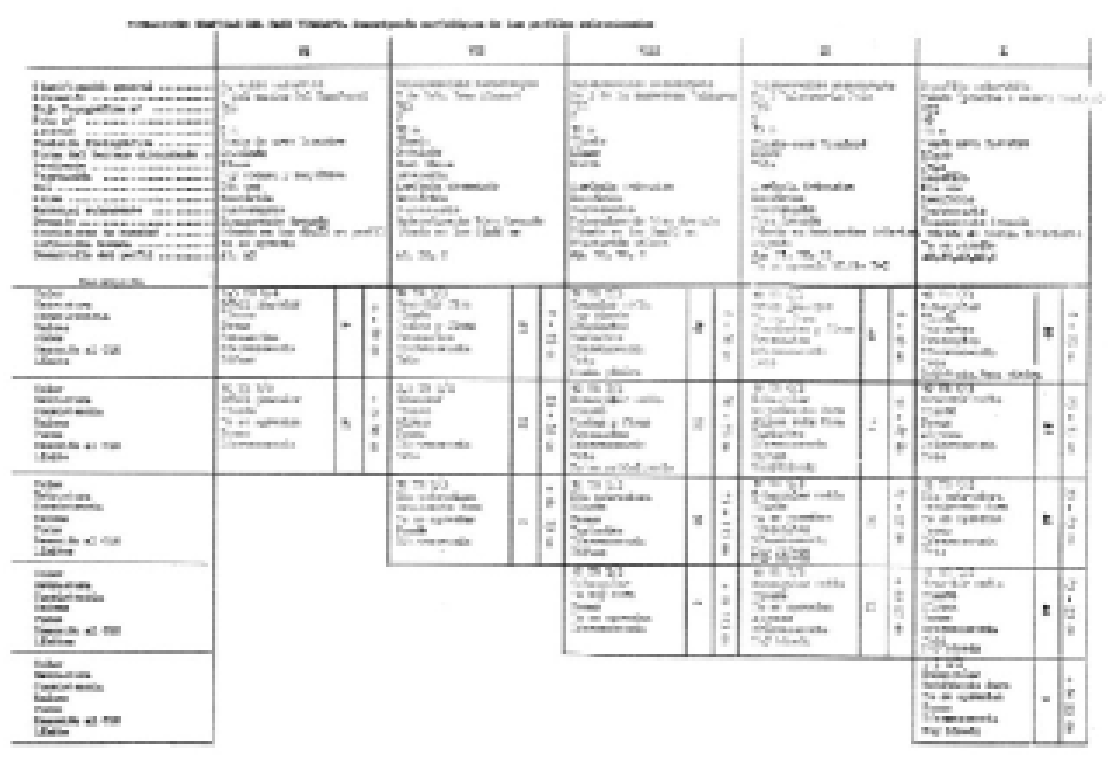




\begin{tabular}{|c|c|c|c|c|c|c|c|c|c|c|}
\hline & Surn. & met. 501 & Stto bane? & 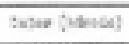 & 20,0s = & 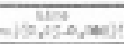 & $(4 x)=0$ & 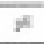 & 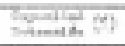 & $\operatorname{sen} 1$ \\
\hline 7 & $\frac{4}{37}$ & 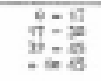 & 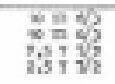 & 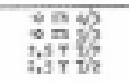 & $\begin{array}{l}\frac{45}{46} \\
4 \sqrt{4} \\
4 x\end{array}$ & 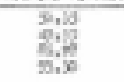 & $\begin{array}{l}\frac{5 x}{40} \\
\frac{30}{46}\end{array}$ & 3 & 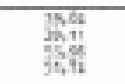 & $\begin{array}{l}\prod_{i=1}=1 \\
\lim _{i=1}=0\end{array}$ \\
\hline Ix & 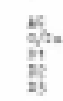 & 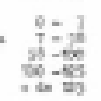 & 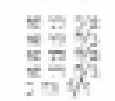 & 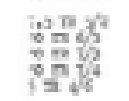 & 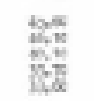 & $\begin{array}{l}5,2 \\
3 ; 0 \\
3 ; 0 \\
3 ; 0\end{array}$ & $\begin{array}{l}7 \infty \\
7 \infty \\
7 \infty\end{array}$ & $\begin{array}{l}3 \\
6\end{array}$ & 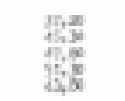 & 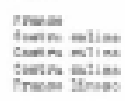 \\
\hline 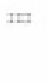 & 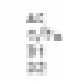 & $\begin{array}{l}0=4 \\
x=8 \\
x=8\end{array}$ & 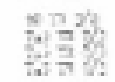 & 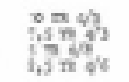 & 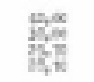 & $\begin{array}{l}a, x \\
3 ; \\
3, x\end{array}$ & $\frac{7 x}{30}$ & s? & $\begin{array}{l}3 y \\
5 y \\
58\end{array}$ & $\lim _{i=n}=1 i n$ \\
\hline u & ial & $\therefore=3$ & 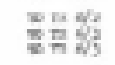 & : & 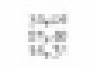 & $\frac{x ; 0}{8 ; i 3}$ & $\begin{array}{l}\text { 14:4 } \\
\text { को, }\end{array}$ & $\ddot{3}$ & 政: & 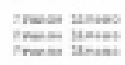 \\
\hline$r$ & $z^{2}$ & $i=\frac{1}{x}$ & $\frac{k}{x} x^{2} x^{2}$ & $8=y^{4}$ & 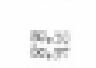 & 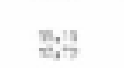 & ligk & 4 & lisin & 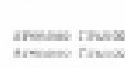 \\
\hline ग & is & $\therefore x$ & 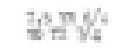 & $\frac{1}{2}=y_{4}^{4}$ & $H_{k}, x$ & wath & $\frac{2.25}{245}$ & $\mathrm{~K}$ & 36 & insan Hens \\
\hline $\mathrm{mz}$ & $\frac{17}{y}$ & 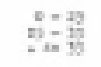 & 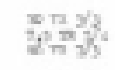 & 을 & 数类 & e: & 20 & 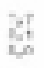 & 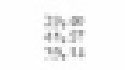 & rnes: menx \\
\hline$m=$ & $\frac{a 1}{x}$ & 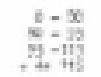 & 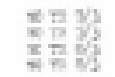 & 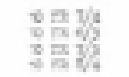 & 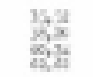 & 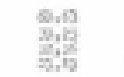 & $\begin{array}{l}2,55 \\
2,35 \\
0.55\end{array}$ & 3 & $\begin{array}{l}\text { Tivit } \\
\text { thit }\end{array}$ & 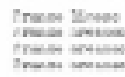 \\
\hline$x$ & 竞 & $\prod_{0}^{t}=\frac{n}{n}$ & 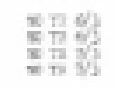 & 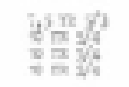 & 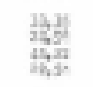 & 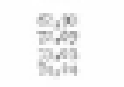 & $\begin{array}{l}3.75 \\
\text { ing } \\
\text { ind? } \\
\text { ind }\end{array}$ & 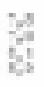 & 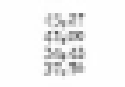 & 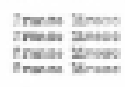 \\
\hline t & 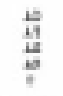 & 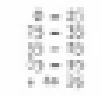 & 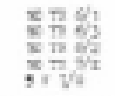 & 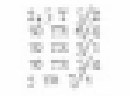 & $\begin{array}{l}3 \% \\
15 \% \\
13 x \\
30 x\end{array}$ & 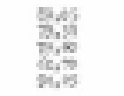 & 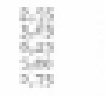 & 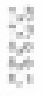 & 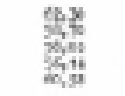 & 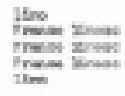 \\
\hline
\end{tabular}




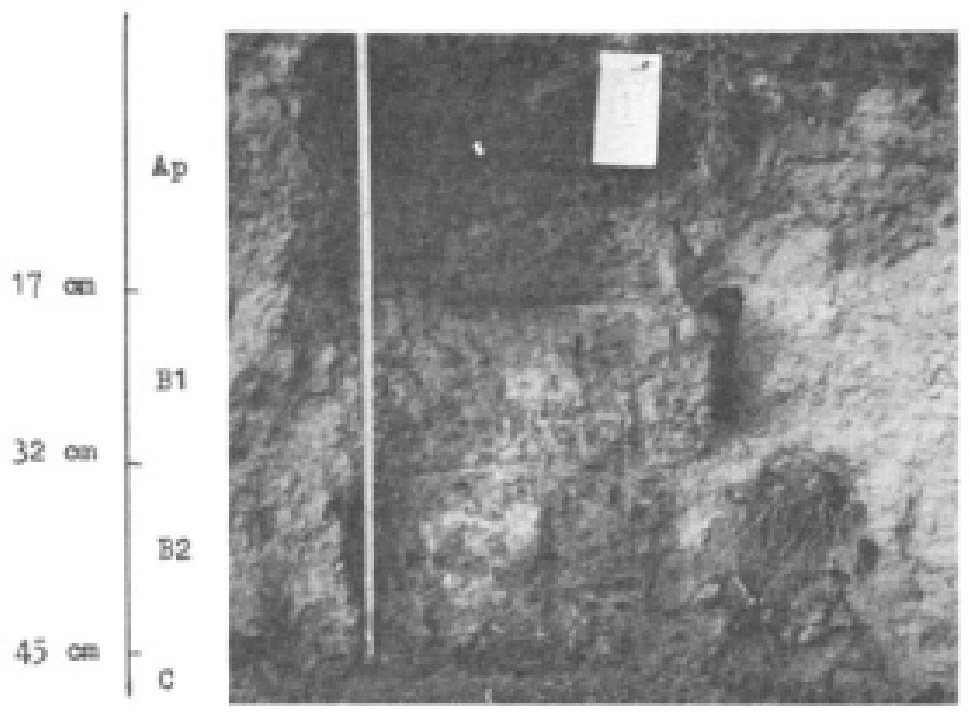

FOTO 1. Perfil I. Suelo pardo calizo (Calcixerollic xerochrepts) sobre sedimentos depositados en el Fondet dels Pinols.

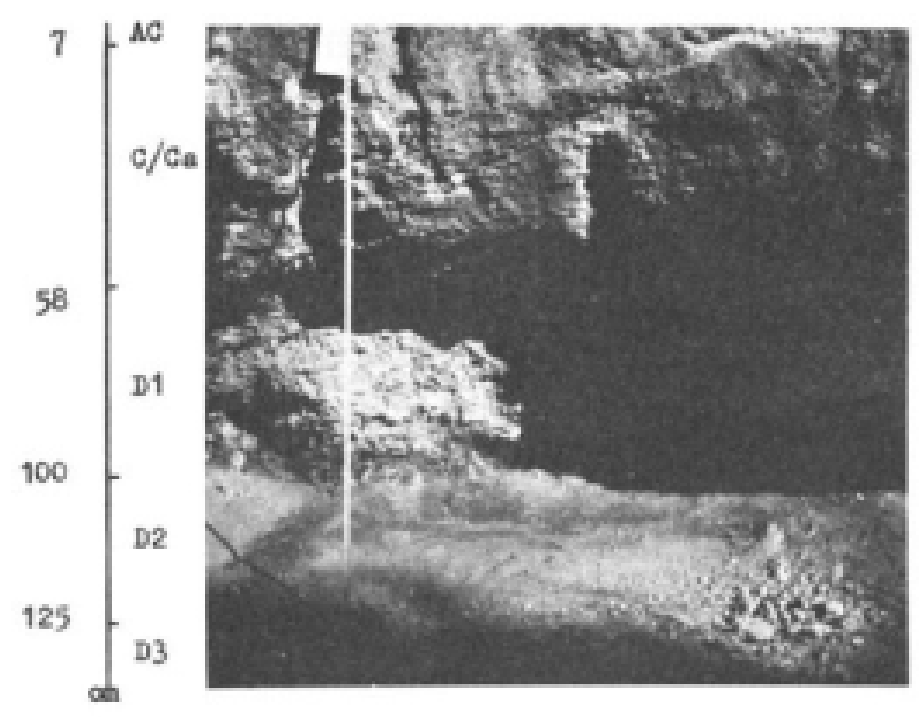

Foto 2. Perfil II. Suelo pardo calizo con costra caliza (Petrocalcic xerochrepts) sobre sedimentos pleistocenos que configuran pequeñas colinas al S de l'Altet. 


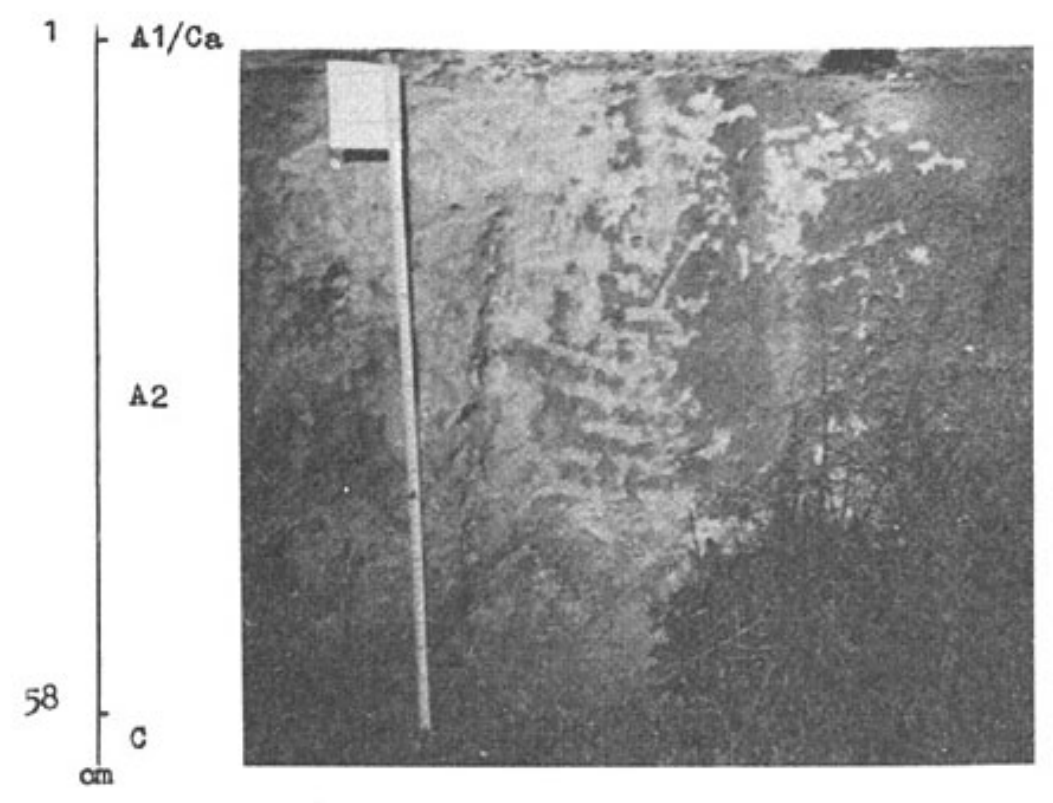

FOTO 3. Perfil V. Regosuelo sobre arenas (Typic xeropsamment) obtenido sobre una duna tirreniense oolítica situada al W de Urbanova a $2 \mathrm{~m}$ sobre el nivel de Agua amarga.

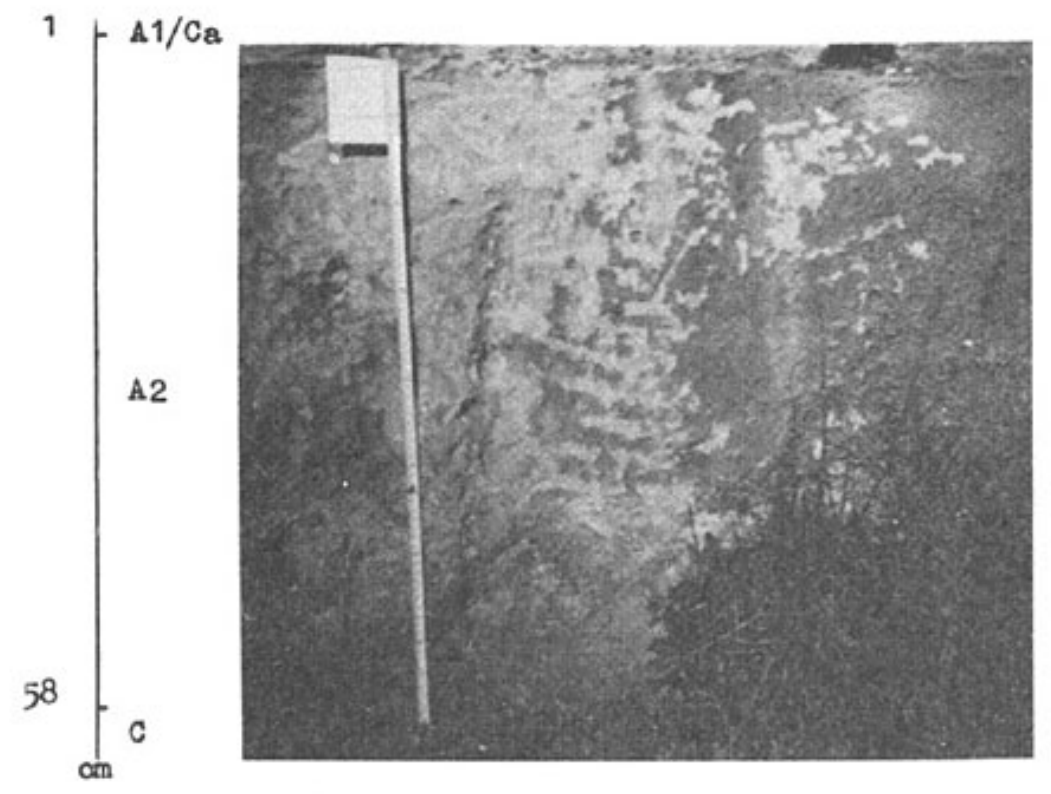

FOTO 4. Perfil VI. Solontchak (Aquollic salorthid) obtenido en el fondo del Clot de Galvany constituido sobre material cuaternario. Textura franco-limosa. 


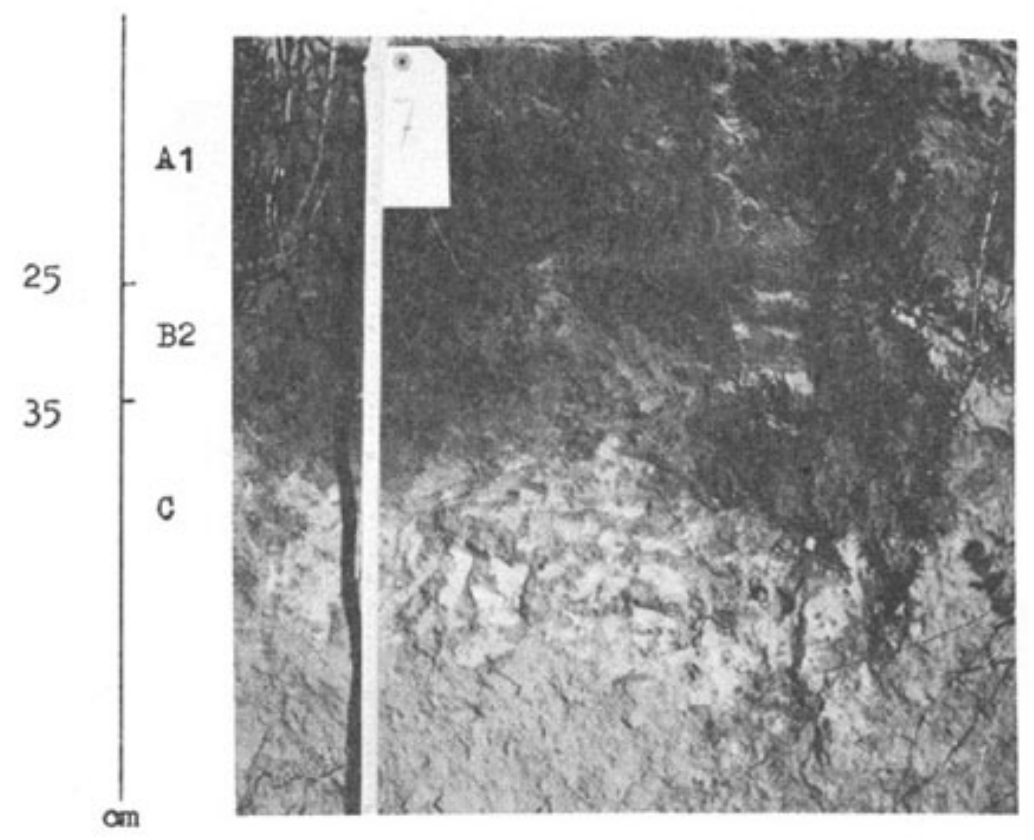

FOTO 5. Perfil VII. Suelo pardo calizo (Calcixerollic xerochepts) obtenido sobre el glacis septentrional del Carabassí. Textura franco arenosa en función de la proximidad al Clot de Galvany.

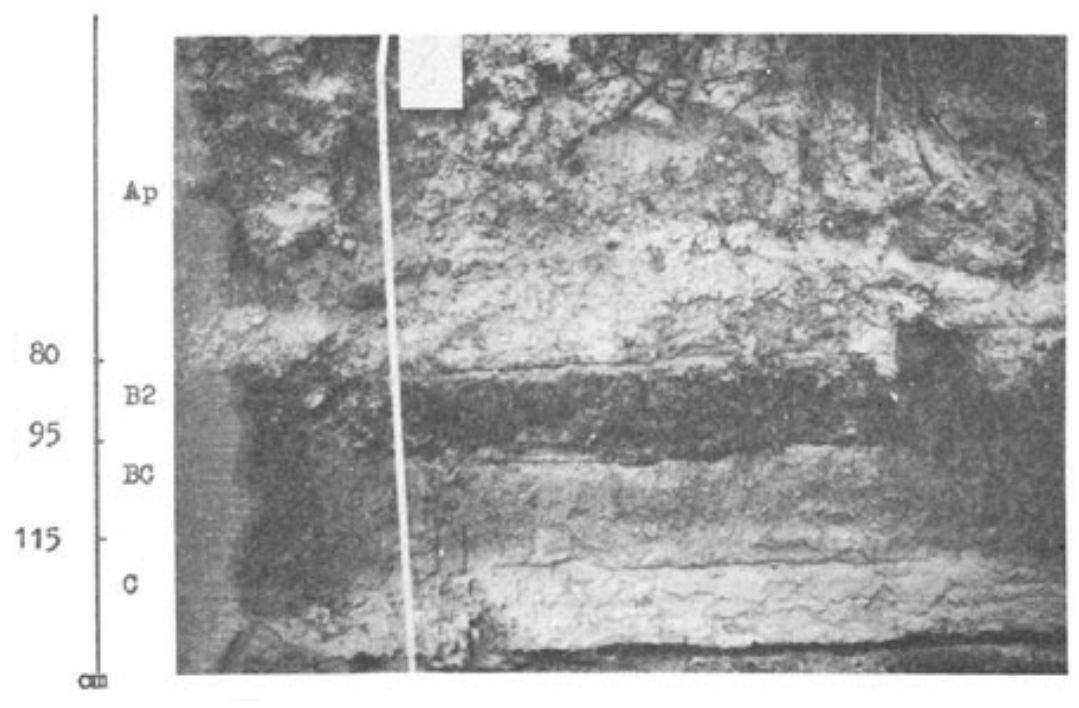

FOTO 6. Perfil VIII. Suelo pardo calizo (Calcixerollic xerochepts) obtenido sobre el glacis de acumulación en el $\mathrm{Km} 3$ de la carretera dels Bassars, en un área con aprovechamiento agrícola intensivo y moderadamente bien drenada. 


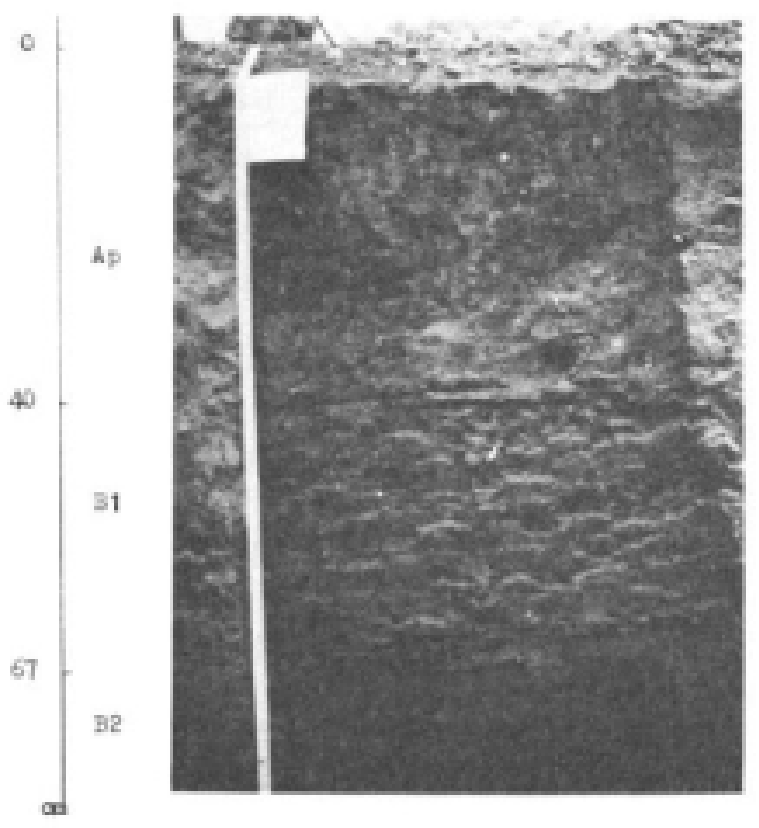

FOTO 7. Perfil IX. Suelo pardo calizo profundo (Calcixerollic xerochrepts) localizado en el $\mathrm{km} 5$ de la carretera dels Bassars sobre el glacis-cono del Vinalopó.

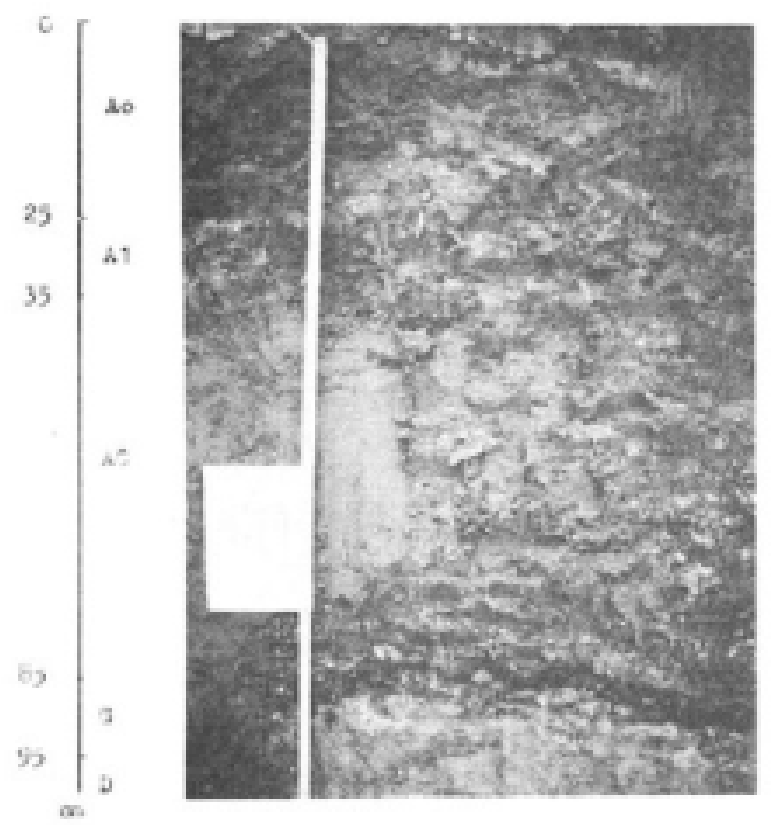

FOTO 8. Perfil X. Solontchak (Aquollic salorthid) obtenido en el Fondó, con claras eflorescencias salinas 
superficiales. Horizonte de seudogley entre 85 y $95 \mathrm{~cm}$ de profundidad, reflejo del antiguo nivel de fondo lacustre. 